\title{
Interculturalidade na formação de professores do campo: análise de uma experiência
}

\author{
Luiz Otávio Costa Marques ${ }^{1}$ \\ ${ }^{1}$ Universidade Federal dos Vales do Jequitinhonha e Mucuri - UFVJM. Faculdade Interdisciplinar em \\ Humanidades. Rodovia MG-367, km 583, Alto da Jacuba, Diamantina - MG. Brasil. luizocmarques@ gmail.com.
}

RESUMO. O presente trabalho visa promover uma reflexão sobre a proposta pedagógica de um curso de licenciatura em Educação do Campo de uma universidade federal brasileira sob a perspectiva teórica da interculturalidade. Entende-se interculturalidade como um projeto contra-epistemológico e contra-hegemônico que preconiza o reconhecimento e o respeito à diversidade cultural e à emancipação política e social de povos subalternizados. Instituído em 2013 para atender à demanda do Edital SESU/SETEC/SECADI $n^{\circ} 2 / 2012$, o curso em pauta tem como objetivo formar professores com habilitação em Ciências da Natureza ou Linguagens e Códigos para atuar nos anos finais do ensino fundamental e no ensino médio de escolas do campo. Este estudo de natureza qualitativa-exploratória se vale de pesquisa documental e bibliográfica. A reflexão teórica se dá a partir da ecologia dos saberes (Santos, 2014), que problematiza as relações de colonialidade do conhecimento científico com outros tipos de conhecimento, assim como das pesquisas sobre interculturalidade (Fleuri, 2001; Walsh, 2009, 2010; Estermann, 2010; Guilherme \& Dietz, 2015) e Educação do Campo (Caldart, 2009; Freitas, 2011; Antunes-Rocha, 2011; Molina \& Freitas, 2011; Molina \& Antunes-Rocha, 2014). Espera-se com este trabalho estimular propostas que dialoguem com o referencial da interculturalidade, ampliando as perspectivas teóricas sobre a formação inicial de professores no contexto da Educação do Campo no Brasil.

Palavras-chave: Interculturalidade, Educação do Campo, Formação de Professores, Políticas Públicas, Colonialidade. 


\title{
Interculturality in the education of countryside teachers: analysis of an experience
}

\begin{abstract}
The present work aims to promote a reflection on the pedagogical proposal of an undergraduate course in Countryside Education from a Brazilian federal university under the theoretical perspective of interculturality. Interculturality is understood as a counter-epistemological and counter-hegemonic project that advocates the recognition and respect for cultural diversity and the political and social emancipation of subalternized peoples. Established in 2013 to meet the demand of SESU/SETEC/SECADI Notice no. 2/2012, the course aims to train teachers in the areas of Natural Sciences or Languages and Codes to work in the final years of elementary education and in high school in rural areas. This qualitative-exploratory study is based on documental and bibliographic research. The theoretical reflection comes from the ecology of knowledge's (Santos, 2014), which problematizes the relations of coloniality of the scientific knowledge with other types of knowledge, as well as studies on interculturality (Fleuri, 2001; Walsh, 2009, 2010; Estermann, 2010; Guilherme \& Dietz, 2015) and Countryside Education (Caldart, 2009; Freitas, 2011; Antunes-Rocha, 2011; Molina \& Freitas, 2011; Molina \& Antunes-Rocha, 2014). It is hoped that this work will stimulate proposals that dialogue with the intercultural reference framework, broadening the theoretical perspectives on the initial education of teachers in the context of Countryside Education in Brazil.
\end{abstract}

Keywords: Interculturality, Countryside Education, Teacher Education, Public Policies, Coloniality. 


\section{Interculturalidad en la formación del profesorado del campo: análisis de una experiencia}

RESUMEN. El presente estudio tiene como objetivo reflexionar sobre la propuesta pedagógica de un grado en Educación del Campo de una universidad federal brasileña por la perspectiva teórica de la interculturalidad. Se comprende interculturalidad como un proyecto contra-epistemológico y contra-hegemónico que aboga por el reconocimiento y respeto a la diversidad cultural y la emancipación social y política de las personas subordinadas. Establecido en 2013 para satisfacer la demanda del Edicto SESU / SETEC / SECADI n ${ }^{\circ} 2 / 2012$, el curso en cuestión tiene como objetivo formar maestros con la especialización en ciencias naturales o lenguajes y códigos para actuar en los últimos años de la escuela primaria y la enseñanza media de las escuelas para los campesinos. Este estudio de naturaleza cualitativa y exploratoria se basa en la investigación bibliográfica y documental. La reflexión teórica se produce desde la ecología de los saberes (Santos, 2014), que analiza las relaciones de colonialidad del conocimiento científico con otros tipos de conocimiento, así como la investigación sobre interculturalidad (Fleuri, 2001; Walsh, 2009, 2010; Estermann, 2010; Guilherme \& Dietz, 2015) y Educación del Campo (Caldart, 2009; Freitas, 2011; Antunes-Rocha, 2011; Molina \& Freitas, 2011; Molina \& Antunes-Rocha, 2014). Se espera que este trabajo estimule las propuestas que se comunican con el marco de la interculturalidad, promoviendo la ampliación de las perspectivas teóricas sobre la formación inicial del profesorado en el contexto de la Educación del Campo en Brasil.

Palabras clave: Interculturalidad, Educación del Campo, Formación Docente, Política Pública, Colonialidad. 


\section{Introdução}

Devido às profundas mudanças estruturais na sociedade contemporânea nas últimas décadas, impulsionadas principalmente pela globalização e pela diáspora de povos perseguidos ou cujos países estão em guerra ou sem condições de sobrevivência, discussões teóricas sobre educação e interculturalidade têm se intensificado de forma considerável. De acordo com as orientações da Organização para a Educação, a Ciência e a Cultura das Nações Unidas - UNESCO (2006, p. 12) sobre educação intercultural, "os conceitos de cultura e educação estão, em essência, entrelaçados", Explica-se que "a cultura modela o conteúdo educacional, modos operacionais e contextos, uma vez que ela molda nossos quadros de referência, nossas maneiras de pensar e agir, nossas crenças e, até mesmo, nossos sentidos" (UNESCO, 2006, p. 12-13). A interculturalidade é definida como um "conceito dinâmico e se refere à relação de constante evolução entre grupos culturais" (UNESCO, 2006, p. 17). De acordo com o documento, a interculturalidade pressupõe multiculturalismo, trocas interculturais equitativas, diálogo e respeito mútuo entre culturas.

Tendo em vista que a discussão sobre interculturalidade e o respeito à diferença e à diversidade cultural na educação emerge no Brasil e na América Latina devido aos movimentos sociais (Fleuri, 2001), este trabalho objetiva discutir aspectos de uma proposta pedagógica de um curso de formação de educadores do campo de uma universidade federal brasileira, o qual é fruto de um desses movimentos, a saber: o Movimento de Educação do Campo.

Surgido nos finais dos anos 1990 e início dos anos 2000, esse movimento, conforme Molina e Freitas (2011), visa reduzir as desigualdades e a precarização do acesso à escolarização nos diferentes níveis no meio rural. Vale frisar que o projeto de Educação do Campo está associado a uma proposta mais abrangente de educação, voltada à emancipação social e política dos sujeitos do campo e à erradicação das desigualdades na sociedade.

Tendo a sua origem no processo de luta dos movimentos sociais para resistir à expropriação de terras, a Educação do Campo vincula-se à construção de um modelo de desenvolvimento rural que priorize os diversos sujeitos sociais do campo, isto é, que se contraponha ao modelo de desenvolvimento hegemônico que sempre privilegiou os interesses dos grandes proprietários de terra no Brasil, e também se vincula a um projeto maior de educação da classe trabalhadora, cujas bases se alicerçam na necessidade da construção de um outro projeto de 
sociedade e de Nação (Molina \& Freitas, 2011, p. 19).

Assim, para nortear a reflexão apresentada neste trabalho, são utilizados estudos sobre a ecologia dos saberes (Santos, 2014), que trata das relações de colonialidade do conhecimento científico com outros tipos de conhecimento na sociedade contemporânea, sobre interculturalidade (Fleuri, 2001; Walsh, 2009, 2010; Estermann, 2010; Guilherme \& Dietz, 2015) e sobre o movimento da Educação no Campo no Brasil (Caldart, 2009; Antunes-Rocha, 2011; Freitas, 2011; Molina \& Freitas, 2011; Molina \& Antunes-Rocha, 2014). No que se refere à metodologia utilizada, neste estudo de caráter qualitativo-exploratório, foram desenvolvidas pesquisas documental e bibliográfica.

Esta reflexão teórica se justifica devido ao fato de que no contexto brasileiro são escassos tanto os estudos como as experiências educativas inovadoras baseados nos princípios da educação intercultural. Além disso, vale lembrar que os casos de racismo, discriminação social e de gênero reportados na mídia em nosso país recentemente são inúmeros, o que indica que a adoção da perspectiva intercultural nas escolas públicas brasileiras possa ser considerada uma alternativa relevante para lidar com essas questões no âmbito escolar e promover mudanças significativas no contexto atual.

Inicialmente, neste estudo, são examinados os conceitos de interculturalidade e educação intercultural nos contextos global e local. Em segundo lugar, um breve histórico da Educação do Campo em nosso país e a visão dessa perspectiva teórica sobre a formação inicial de professores para atuar no meio rural são apresentados. Em seguida, as políticas educacionais brasileiras voltadas à Educação do Campo que originaram a instituição de cursos superiores de formação de professores do campo em nosso país, como a licenciatura cuja proposta pedagógica é objeto de análise neste trabalho, são examinadas. Ao final, essa proposta pedagógica é descrita e analisada, visando ampliar perspectivas teóricas sobre a formação inicial de professores no contexto da Educação do Campo.

\section{A interculturalidade e a educação intercultural}

A noção de interculturalidade preconizando relações de interdependência entre culturas dialoga com a visão do filósofo e teólogo suíço Josef Estermann, estudioso das culturas indígenas da América Latina. Para o autor, a 
interculturalidade é definida como "relações simétricas e horizontais entre duas ou mais culturas, visando enriquecêlas mutuamente e contribuir para uma maior plenitude humana" (Estermann, 2010, p. 33). Ele aponta ainda que o diálogo intercultural é um processo de aprendizagem e transformação entre as pessoas envolvidas, resultando em alteridade cultural.

Um verdadeiro diálogo nunca é conservador, isto é: nunca se sabe como se sairá de um diálogo. A própria postura e identidade podem sofrer alterações ao longo deste processo dialógico e no final um/a não é mais a mesma pessoa que era no momento em que o processo foi iniciado. (Estermann, 2010, p. 42).

Sobre a relação entre interculturalidade e educação, Walsh (2010) explica que esse tema passa a estar presente nos debates públicos e nas políticas educacionais da América Latina a partir dos anos 1980. A autora explica que, embora esse amparo legal seja fruto das lutas de movimentos sociais, visando à emancipação política e social das populações subalternizadas, interculturalidade também pode ser vista a partir de uma perspectiva definida pelo autor peruano Fidel Tubino (2005 apud Walsh, 2010, p. 77-78) como "funcional". Esta se articula com o sistema de poder dominante e a lógica do neoliberalismo:
... a perspectiva (funcional) de interculturalidade ancora-se no reconhecimento da diversidade $\mathrm{e}$ diferença culturais, objetivando a inclusão da mesma no interior da estrutura social estabelecida. A partir desta perspectiva - que visa promover o diálogo, a convivência e a tolerância -, a interculturalidade é "funcional" para o sistema existente, não toca as causas da assimetria e da desigualdade sociais, tampouco "questiona as regras do jogo", por isso "é perfeitamente compatível com a lógica do modelo neoliberal existente" (Walsh, 2010, p. 77-78).

Essa

perspectiva

de interculturalidade contrapõe-se à perspectiva de interculturalidade crítica, defendida por Walsh (2010, p. 76), como um "projeto político-social-epistêmico e como pedagogia de-colonial ${ }^{i i}$, dando pistas para uma práxis distinta". Ou seja, o projeto é político - visa mudar as configurações coloniais de poder no modelo político dominante no mundo -, social - ambiciona extinguir as desigualdades sociais e culturais -, epistêmico - valoriza outras formas de produção de saberes e conhecimentos, além dos científicos e tecnológicos -, e ético - objetiva acabar com as relações de exclusão, subalternização, discriminação e de raça. É uma pedagogia decolonial, pois visa transformar a visão modernista, ocidental e capitalista de educação para uma visão de educação voltada para a 
transformação, humanização e a decolonização.

Walsh (2010) ressalta que a interculturalidade crítica é um projeto, ou seja, ainda não existe na prática. No campo educacional da América Latina, destaca algumas tentativas de mudança como a educação intercultural bilíngue nos anos 1980, a qual estabelecia um programa de educação plurilíngue e multiétnica para os povos indígenas, e as reformas constitucionais dos anos 1990, que "tanto na sua prática como na sua conceituação, esforçaram-se mais por adequar a educação às exigências da modernização e do desenvolvimento do que 'interculturalizar' o sistema educativo" (Walsh, 2010, p. 83). Em outras palavras, eram propostas que reforçavam o discurso da diversidade étnica e cultural, mas que na prática não promoviam nenhuma mudança a favor da interculturalidade crítica.

Conforme a autora, somente a partir do século XXI surgem propostas que mais se aproximam de uma educação crítica intercultural. Ela cita, como exemplo, um novo modelo educativo no México denominado "Educação Intercultural", o qual se estende do ensino básico até a universidade, tendo como eixo central a interculturalidade. Apesar de ser um grande avanço, o modelo, de acordo com a pesquisadora, ainda associa a questão da interculturalidade com os indígenas.

\begin{abstract}
Aparentemente, a compreensão do intercultural ainda está focada no indígena; embora exista um reconhecimento de que a educação intercultural é para todos, sua proposta facilmente acaba sendo um pouco mais do que a incorporação de temas relacionados à diversidade linguística e cultural. Pensar a educação intercultural como um processo de estudo e aprendizagem inter-epistêmicos, ainda parece distante, na maioria dos países, de uma nova prática e política educativas. (Walsh, 2010, p. 85).
\end{abstract}

No contexto brasileiro, as propostas educacionais que dialogam com a perspectiva teórica da interculturalidade são poucas. Fleuri (2001) aponta que a elaboração de propostas de trabalho pedagógico que considerem efetivamente a complexidade cultural do Brasil encontra dificuldades, uma vez que são raros os estudos e as experiências educativas inovadoras sobre esse tema. Já na América Latina, explica o autor, são várias as experiências educativas voltadas a uma perspectiva que respeita a diversidade cultural de diferentes grupos sociais $\mathrm{e}$ culturais marginalizados. Como apontado pelo autor, essas experiências educativas surgiram principalmente a partir dos anos 1950 com os movimentos de cultura popular, que posteriormente vieram a ser chamados de educação popular. 
No Brasil, trabalhos educativos e iniciativas que valorizavam a cultura popular surgiram no início da década de 1960 com as grandes mobilizações urbanas e camponesas. Entre essas iniciativas, as quais foram lideradas por intelectuais, estudantes e movimentos eclesiais, Fleuri (2001) destaca os Centros Populares de Cultura (CPGs), o Movimento de Educação de Base (MEB), o Movimento de Cultura Popular (MCP) e a campanha "De pé no chão também se aprende a ler". Como exemplo de trabalho educativo, o pesquisador cita a proposta de educação de adultos de Paulo Freire.

Fleuri (2001) explica que, com o Golpe Militar de 1964, esses movimentos passaram a ser controlados e censurados, o que favoreceu a homogeneização e a alienação cultural no país. Entretanto, no final dos anos 1970, segundo o autor, esse silenciamento começou a ser rompido, favorecendo o surgimento no cenário nacional de movimentos populares voltados às lutas sociais no plano econômico-político. Destaca, entre esses movimentos, as associações de moradores, as comunidades eclesiais de base (CEBs), os movimentos operários e sindicais e os movimentos ligados à questão agrária. Esses movimentos, de acordo com Fleuri (2001), começaram a se articular transversalmente com a defesa de suas identidades de caráter étnico (tal como os movimentos dos indígenas e dos negros), de gênero (tal como os movimentos das mulheres e dos homossexuais) e de geração (tal como os movimentos de meninos e meninas de rua e da terceira idade). Para o autor, a perspectiva da diversidade e das relações culturais emergentes nos movimentos sociais é a base da educação intercultural na América Latina e, particularmente, no Brasil. Na visão do autor, "é a partir deste ponto de vista que pensamos em estabelecer o diálogo com os estudos que vêm se fazendo hoje no campo da educação intercultural" (Fleuri, 2001, p. 48).

Nessa perspectiva, a diferença e a identidade cultural de cada grupo social são reconhecidas, porém, ao mesmo tempo, busca-se "desenvolver a interação e a reciprocidade entre grupos diferentes, como fator de crescimento cultural e enriquecimento mútuo" (Fleuri, 2000, p. 49). No que se refere à prática pedagógica de educandos provenientes de grupos socialmente marginalizados e excluídos, a interculturalidade pode ser vista como uma proposta para superar o monoculturalismo na educação.

O foco central da prática educativa deixa de ser a transmissão de uma cultura homogênea e coesa. A preocupação fundamental da educação passa a ser a elaboração da 
diversidade de modelos culturais que interagem na formação dos educandos. Tal deslocamento de perspectiva legitima as culturas de origem de cada indivíduo e coloca em xeque a coesão da cultura homogênea. (Fleuri, 2001, p. 50).

Cabe aqui questionar: como seria o trabalho pedagógico sob o ponto de vista da educação intercultural no contexto brasileiro? Conforme a opinião de Fleuri (2001), esse trabalho consistiria na problematização e desconstrução de imagens e estereótipos presentes na realidade brasileira, os quais encobrem grande parte dos conflitos relacionados a questões interculturais e que "enfraquecem o enorme potencial que pode advir do confronto e da interação crítica entre diferentes grupos sociais" (Fleuri, 2001, p. 50). O autor acrescenta que

Esta perspectiva problematizadora da dimensão intercultural pode oferecer aos agentes - institucionais ou populares - instrumentos indispensáveis à sua prática educativa. De modo particular, proporcionar meios para promover a formação da autoconsciência - e portanto de "presença" e ação - em sujeitos que vivem em ambientes marginalizados (rurais e urbanos). A perspectiva intercultural da educação pode, ainda, estimular os movimentos sociais a focalizar, na própria reflexão e na própria prática, a dialética identidade e alteridade. $\mathrm{Ou}$ seja, estimular a consciência das diferenças e das relações entre os agentes e os pontos de vista que nele se articulam. (Fleuri, 2001, p. 50).
Ou seja, a educação intercultural pressupõe práticas educativas que promovam o reconhecimento da diversidade cultural por meio da reflexão sobre questões de identidade e alteridade. Assim, essa problematização pode ser vista como um objetivo a ser atingido no contexto escolar, uma vez que prepara os educandos para lidar com a diferença no seu dia a dia, contribuindo para reduzir preconceitos e discriminação de todos os tipos.

Fleuri (2001), corroborando a opinião de Nanni (1988, p. 50), aponta que a interação promovida pela educação intercultural pode favorecer o crescimento da cultura pessoal dos indivíduos e a mudança das estruturas e relações sociais que impedem a construção de uma sociedade mais justa e solidária.

A educação intercultural se configura como uma pedagogia do encontro até as suas últimas consequências, visando promover uma experiência profunda e complexa, em que o encontro/confronto de narrações diferentes configura uma ocasião de crescimento para o sujeito, uma experiência não superficial e incomum de conflito/acolhimento. (Fleuri, 2001, p. 53, grifos do autor).

De acordo com Nanni (1988, p. 5155 apud Fleuri, 2001, p. 54), para que a educação intercultural consiga alcançar seus objetivos no contexto escolar são 
necessárias as seguintes mudanças nas práticas educativas:

1. A realização do princípio da igualdade de oportunidades: A educação intercultural requer que se trate nas instituições educativas os grupos populares não como cidadãos de segunda categoria, mas que se reconheça seu papel ativo na elaboração, escolha e atuação das estratégias educativas. Além disso, é preciso repensar as funções, os conteúdos e os métodos da escola, de modo a se superar o seu caráter monocultural.

2. A reelaboração dos livros didáticos, adoção de técnicas e de instrumentos multimediais. A educação intercultural requer profundas transformações no modo de educar. A prática educativa é estimulada a se tornar sempre mais interdisciplinar e multimediais. De modo particular, dever-se-á utilizar as técnicas e as metodologias ativas, do jogo à dramatização. Mas principalmente os livros didáticos deverão sofrer profundas mudanças. Estes são escritos geralmente na perspectiva da cultura oficial e hegemônica, e não para alunos pertencentes a "muitas culturas", diferentes entre si, justamente no modo de interpretar fatos, eventos, modelos de comportamento, ideias, valores. E talvez sejam usados justamente por aqueles alunos cujas culturas são representadas e julgadas, a partir da cultura hegemônica, de modo preconceituoso e discriminatório.

3. A formação e a requalificação dos educadores são talvez o problema decisivo, do qual depende o sucesso ou o fracasso da proposta intercultural. O que está em jogo na formação dos educadores é a superação da perspectiva monocultural e etnocêntrica que configura os modos tradicionais e consolidados de educar, a mentalidade pessoal, os modos de se relacionar com os outros, de atuar nas situações concretas.

No contexto educacional brasileiro, a implementação dessas mudanças pode ser vista como um grande desafio, uma vez que o monoculturalismo prevalece nas instituições de ensino e pesquisa. No entanto, começam a surgir propostas educacionais enraizadas nos movimentos sociais que dialogam com a educação intercultural, como a da Educação do Campo, discutida a seguir.

\section{A Educação do Campo e a formação de educadores}

Como apontado por Freitas (2011), a Educação do Campo é fruto da luta de movimentos sociais empreendida no Brasil a partir da primeira metade do século $\mathrm{XX}$, período em que houve o início da industrialização, da urbanização e do consequente êxodo rural. Os agentes sociais envolvidos na Educação do Campo reivindicavam, além da reforma agrária, o direito a uma educação pública de qualidade no contexto rural brasileiro, que, ainda hoje, é caracterizado por contrastes, precariedade e desigualdades sociais e educacionais. De um lado, há um modelo de desenvolvimento do campo que privilegia os proprietários de grandes extensões de terra, a monocultura e o agronegócio voltado para a produção de 
commodities (Caldart, 2009; Molina \& Freitas, 2011) e, do outro, uma proposta contra-hegemônica de desenvolvimento que favorece os pequenos proprietários de terras, a agricultura familiar e, mais recentemente, a agroecologia. Neste modelo, a terra não é vista pelos sujeitos do campo apenas como um espaço de produção de alimentos, mas principalmente como um espaço privilegiado de vida comunitária e constituição identitária.

Desse modo, a realidade desses sujeitos demanda uma proposta de educação diferenciada da proposta das escolas que atendem às populações dos territórios urbanos. A proposta educacional de escolas do campo requer uma abordagem que privilegie metodologias específicas, voltadas à diversidade sociocultural e linguística dos estudantes do campo. No que tange à pedagogia do trabalho escolar, Molina e Freitas (2011) defendem que a escola do campo deva vincular os processos de ensino e aprendizagem à realidade social dos seus educandos. Essas vinculações, segundo as pesquisadoras, abrem possibilidades para a ressignificação do conhecimento científico, o que pode levar os educandos a ter maior autonomia e assumir uma postura mais crítica no processo de construção de conhecimento.
Além de contribuir com a construção de autonomia dos educandos, essas articulações propiciam a internalização da criticidade necessária à compreensão da neutralidade científica, com a localização da historicidade dos diferentes conteúdos e dos contextos sócio-históricos nos quais foram produzidos. (Molina \& Freitas, 2011, p. 27).

No que se refere ao funcionamento da escola do campo e ao perfil de professor que nela atua, conforme Antunes-Rocha (2009), exige-se uma organização do tempo e espaço escolar articulada com a dinâmica da vida no campo e um perfil acadêmico distinto de professor. Este deve ter uma formação acadêmica ampla e diferenciada, que o capacite para trabalhar de forma transdisciplinar, superando a lógica de formação multidisciplinar presente no modelo de formação docente nas universidades brasileiras. Além disso, é necessário que esse profissional esteja habilitado para atuar em diferentes níveis do ensino fundamental e do ensino médio e em diferentes formas de organização curricular. É muito comum, por exemplo, a existência de escolas do campo que trabalham em regime de alternância ${ }^{\text {iii }}$ e com turmas multisseriadas, nas quais o professor trabalha conteúdos diversos com alunos de diferentes anos escolares e idades na mesma sala de aula. Ou seja, um docente sem uma formação acadêmica 
diferenciada - por áreas de conhecimentos, que o possibilite atuar de forma crítica e inter/transdisciplinar nesse contexto -, pode não dar conta de lidar com essa realidade.

A proposta pedagógica das licenciaturas de Educação do Campo instituídas pelas políticas educacionais brasileiras - contrapondo-se à ideia iluminista e colonialista de educação que focaliza a transmissão do conhecimento acadêmico, definido como "conhecimento universal" - objetiva articular, de forma dialética, diferentes formas de produção de conhecimento. Essa articulação visa à transformação das realidades em que estão inseridos os estudantes, seja a realidade de suas comunidades de origem, seja a realidade monocultural e monoepistêmica das instituições em que participam ou que futuramente participarão como educadores.

Em oposição à lógica da monocultura do conhecimento científico, Santos (2014) propõe a epistemologia da ecologia dos saberes, a qual seria na realidade uma proposta contraepistemológica. O autor explica que

... a ecologia dos saberes é basicamente uma contraepistemologia. Isso implica renunciar a qualquer epistemologia geral. Em todo o mundo, não existem somente formas muito diversas de conhecimento da matéria, da sociedade, da vida e do espírito, mas também muitos e distintos conceitos sobre o que é considerado conhecimento e os critérios que podem ser utilizados para validá-lo. A este respeito, o que é válido para a teoria é válido para a epistemologia também. No período de transição em que estamos entrando, em que ainda prevalecem as versões abissais da totalidade e da unidade do conhecimento, precisamos provavelmente de uma posição epistemológica geral residual ou negativa para avançarmos: uma epistemologia geral da impossibilidade de uma epistemologia geral. (Santos, 2014, p. 192).

Ele ainda esclarece que, do ponto de vista epistemológico, as sociedades capitalistas são caracterizadas por favorecer práticas nas quais 0 conhecimento científico prevalece e a falta dele pode ser considerada como um fator desqualificador. Para o autor, esse "não conhecimento" ou ignorância significa não aprender ou ter acesso às descobertas e definições científicas. Dessa forma, conhecimentos diferentes dos científicos são desvalorizados ou ignorados. Sabe-se, ainda, que a difusão do conhecimento científico não é uniforme socialmente, o que implica ainda no favorecimento de determinados grupos sociais e desqualificação de outros. Entretanto, vale apontar, isso não implica que se deva negar o conhecimento científico, mas, nas palavras de Santos (2014, p. 189), “usá-lo 
em um contexto mais amplo de diálogo com outros tipos de conhecimentos".

Segundo o pesquisador, como todos os tipos de conhecimentos são incompletos (não dão conta de superar todas as possíveis intervenções no mundo), diálogos e debates entre eles devem ser promovidos com o objetivo de superar certo "não conhecimento". Conforme Santos (2014, p. 189),

Do ponto de vista da ecologia dos saberes, os limites externos implicam reconhecer intervenções alternativas somente consideradas possíveis por outros tipos de saberes. Uma das características específicas do conhecimento hegemônico é que elas somente reconhecem limites internos. O uso contra-hegemônico da ciência moderna constitui uma exploração paralela e simultânea dos seus limites internos e externos.

Para superar a incompletude dos conhecimentos, Santos (2014), assim como Walsh (2010), defende abordagens interculturais, pós-coloniais e emancipatórias na educação que permitiriam o reconhecimento da pluralidade de sistemas de conhecimento e uma possível articulação dialética entre eles. $\mathrm{O}$ autor aponta que essas abordagens seriam uma alternativa à ciência moderna e, em oposição à visão de Walsh (2010), segundo a qual a interculturalidade crítica ainda é um projeto, afirma que elas já estão presentes há certo tempo no mundo com resultados férteis, especialmente no sul global, onde a relação entre o conhecimento hegemônico e o não hegemônico tende a ser menos igualitária.

Vale salientar que essa "epistemologia contraepistemológica" defendida por Santos (2014) está em consonância com a proposta de formação de professores sob a perspectiva teórica da Educação do Campo. Ambas questionam a hegemonia do conhecimento científico e privilegiam o diálogo intercultural na construção dos saberes em espaços educacionais. Conforme Sant'Anna e Marques (2015, p. 732),

Os projetos de formação de educadores do campo devem, portanto, oportunizar espaços formativos que extrapolem os muros das universidades, que levem o discente a interagir com a diversidade do campo, com os seus saberes e formas de construção e apropriação do conhecimento.

\section{Políticas educacionais brasileiras para o desenvolvimento da Educação do Campo}

Nesta seção, políticas e programas educacionais lançados pelo governo federal brasileiro são apresentados e discutidos, com o objetivo de contextualizar o curso de Licenciatura em Educação do Campo, cuja proposta pedagógica é o objeto de análise deste 
estudo. Para isso, foram selecionadas algumas dessas ações governamentais para discussão, tendo em vista os objetivos deste estudo. Entretanto, é importante destacar que há outros marcos legais importantes na Educação do Campo e o caminho percorrido pelos movimentos sociais e sindicais do campo até chegar a essas conquistas tem sido árduo e longo.

No final dos anos 1990 e início dos anos 2000, surgiram propostas do governo federal, impulsionadas principalmente por movimentos sociais, sindicatos de trabalhadores rurais e universidades públicas de ensino superior, visando combater as grandes desigualdades sociais e educacionais no meio rural. Molina, Montenegro e Oliveira (2009, p. 175), baseando-se em dados do IBGE - PNAD de 2004-2007, apontam números relacionados a essas desigualdades:

A taxa de analfabetismo da população de 15 anos ou mais, que apresenta um patamar de $23,3 \%$ na área rural, é mais de três vezes superior àquela da zona urbana, que se encontra em 7,6\%. A escolaridade média da população de 15 anos ou mais, que vive na zona rural é de 4,5 anos, enquanto no meio urbano, na mesma faixa etária, encontra-se em 7,8 anos. Ocorrem significativas diferenças em relação à escolaridade média das populações rural e urbana entre as regiões brasileiras, ficando o território do campo em desvantagem em todas elas.
Entre as propostas voltadas para o combate às desigualdades sociais $\mathrm{e}$ educacionais no campo, destaca-se o Programa Nacional de Educação na Reforma Agrária (Pronera). Conforme o Manual de Operações do Pronera (2016), o programa, criado em 1998, tornou-se uma política pública de Educação do Campo por meio do Decreto $\mathrm{n}^{\circ} 7.352$, de 4 de novembro de 2010, com o objetivo de propor e apoiar projetos de educação voltados para o desenvolvimento das áreas de assentamento da reforma agrária. Além de possibilitar a oferta de cursos de educação básica (alfabetização, ensinos fundamental e médio), ensino técnico profissionalizante de nível médio, cursos superiores e de especialização, o Pronera desenvolve projetos para formar e capacitar educadores para atuar nesses espaços como multiplicadores e organizadores de atividades educativas comunitárias.

Cabe salientar que o Decreto $\mathrm{n}^{\circ}$ 7.352/2010 é considerado um dos marcos legais mais importantes da Educação do Campo no Brasil. Por meio desse decreto, é instituída a política de Educação do Campo no país. No documento, os artigos $1^{\circ}$ e $2^{\circ}$ definem os sujeitos do campo e as escolas do campo, conceitos fundantes na Educação do Campo. 
I - populações do campo: os agricultores familiares, os extrativistas, os pescadores artesanais, os ribeirinhos, os assentados e acampados da reforma agrária, os trabalhadores assalariados rurais, os quilombolas, os caiçaras, os povos da floresta, os caboclos e outros que produzam suas condições materiais de existência a partir do trabalho no meio rural; e II - escola do campo: aquela situada em área rural, conforme definida pela Fundação Instituto Brasileiro de Geografia e Estatística - IBGE, ou aquela situada em área urbana, desde que atenda predominantemente a populações do campo.

Conforme Molina e Freitas (2011), outro programa de educação conquistado por meio das lutas dos movimentos sociais e sindicais do campo foi o Programa de Apoio à Formação Superior em Licenciatura em Educação do Campo (Procampo), instituído pela Secretaria de Educação Continuada, Alfabetização, Diversidade e Inclusão (Secadi) do Ministério da Educação (MEC). Estabelecido por meio do Edital de Convocação no 9, de 29 de abril de 2009, o programa convocou as universidades públicas para ofertar cursos de Licenciatura em Educação do Campo com habilitação em, no mínimo, duas das áreas de conhecimento previstas para a docência multidisciplinar, a saber: Linguagens e Códigos, Ciências Humanas e Sociais, Ciências da Natureza, Matemática e Ciências Agrárias. Como indicado no programa, essas licenciaturas interdisciplinares tinham como objetivo formar educadores para atuar nos anos finais do ensino fundamental e no ensino médio em escolas do campo.

Apesar de serem considerados um grande avanço nas políticas de formação de educadores do campo, esses cursos, viabilizados por meio deste edital, apresentavam limitações em relação ao atendimento da grande demanda de formação de professores para atuar no campo. Molina e Antunes-Rocha (2014) explicam que dentre as limitações estava o fato de esses cursos não terem a garantia de continuidade nas instituições de ensino superior, uma vez que o edital previa a abertura de turmas específicas por projeto. Ou seja, finalizando o projeto, extinguia-se o curso. Entretanto, segundo as autoras, devido à pressão do Movimento da Educação do Campo, a correção da oferta única de curso foi feita por meio da publicação do

Edital SESU/SETEC/SECADI $\quad n^{\circ} \quad 2 / 2012$, convocando as universidades a tornar os cursos de Licenciatura em Educação do Campo perenes nessas instituições.

Essa medida visou não só corrigir a oferta única, característica dos editais anteriores, mas principalmente dar institucionalidade e permanência a esta proposta de formação de educadores. Uma das principais conquistas do Movimento da Educação do Campo, 
nesta perspectiva de permanência, foi a conquista de 600 vagas de concurso docente no âmbito da educação superior para a oferta destas Licenciaturas. (Molina \& AntunesRocha, 2014, p. 240).

Em 2013, para assegurar as ações políticas de melhoria da Educação do Campo e, consequentemente, da formação de professores para atuar no contexto rural, foi instituído o Programa Nacional de Educação do Campo (Pronacampo) por meio da Portaria $n^{\circ} 86$, de $1^{\circ}$ de fevereiro de 2013. O documento estabelece em seu artigo $1^{\circ}$ que o programa "consiste em um conjunto articulado de ações de apoio aos sistemas de ensino para a implementação da política de Educação do Campo, conforme disposto no Decreto $\mathrm{n}^{\mathrm{o}} 7.352$, de 4 de novembro de 2010 ".

Uma das licenciaturas em Educação do Campo instituídas no Brasil por meio dessas políticas públicas do governo federal é a da Universidade Federal dos Vales do Jequitinhonha e Mucuri UFVJM, localizada no estado de Minas Gerais, cuja proposta pedagógica será discutida a seguir.

\section{A Licenciatura em Educação do Campo da Universidade Federal dos Vales do Jequitinhonha e Mucuri - LEC-UFVJM e sua proposta pedagógica}

Segundo o Projeto PolíticoPedagógico da Licenciatura em Educação do Campo - LEC da Universidade Federal dos Vales do Jequitinhonha e Mucuri (2014), essa graduação foi instituída em 2013 para atender a demanda do Edital SESU/SETEC/SECADI $\mathrm{n}^{\circ} \quad 2 / 2012$, apontado anteriormente. Como discutido, esse edital faz parte das políticas públicas do governo federal, materializadas por meio de resoluções e programas nacionais, visando subsidiar técnica e financeiramente os estados, o Distrito Federal e os municípios brasileiros na instituição de uma política nacional de Educação do Campo.

A LEC está inserida na UFVJM, cuja fundação teve por objetivo atender a demanda por instituições de nível superior de uma vasta região que abrange o norte e nordeste do estado de Minas Gerais, uma vez que a maioria das instituições federais de ensino superior mineiras está localizada mais ao sul do estado. Conforme o Plano de Desenvolvimento Institucional da UFVJM (2012), a universidade foi criada com a transformação da Faculdade de Odontologia de Diamantina, fundada em 30 de setembro de 1953 por Juscelino Kubitschek de Oliveira, governador do estado naquele ano, em universidade federal, por meio da Lei $n^{\circ} 11.173$ de 6 de setembro de 2005, publicada no Diário Oficial da União em 8 de setembro de 2005. 
Estima-se que mais de dois terços da população do Vale do Jequitinhonha, região na qual a sede da universidade está localizada, vive no meio rural, segundo o Portal Polo do Jequitinhonha (2017). Essa região, situada ao nordeste de Minas Gerais, juntamente com a do Vale do Mucuri, é exemplo de disparidades regionais no estado, apresentando os mais baixos índices de renda domiciliar per capita média e IDH-M dentre as regiões mineiras (PDI - UFVJM, 2012, p. 23), o que pode ser considerado um fator que justifica a implantação da LEC na UFVJM.

O objetivo geral do curso é a formação crítica e contextualizada de professores, voltada à transformação política e social do meio rural e de suas escolas. Com duração de 4 anos, a LECUFVJM visa formar professores com habilitação em Ciências da Natureza ou Linguagens e Códigos para atuar nos anos finais do ensino fundamental e no ensino médio de escolas do campo. Uma de suas características principais e a qual o diferencia dos demais é a sua matriz curricular inter/transdisciplinar, a qual apresenta componentes curriculares ${ }^{\mathrm{iv}} \mathrm{em}$ áreas distintas do conhecimento que se articulam de forma orgânica para discutir temas transversais relacionados à Educação do Campo. Estes perpassam os oito módulos do curso. Entre os temas transversais, destacam-se os seguintes: territórios e comunidades do campo, sujeitos do campo, o educador no contexto do campo e a relação entre saberes. A função desses temas é articular os conhecimentos produzidos no Tempo Universidade e no Tempo Comunidade para a elaboração semestral do Relatório de Tempo Comunidade ${ }^{\mathrm{v}}$, o qual é orientado pelos professores formadores do curso. Além da produção desse trabalho, outra característica da matriz curricular da LECUFVJM que se opõe à fragmentação do conhecimento e fortalece a dimensão interdisciplinar do curso é a presença de componentes curriculares que podem ser ministrados por dois ou mais professores de diferentes áreas do conhecimento.

\begin{abstract}
Nesse contexto, tão importante quanto a atuação em sala de aula, é a construção coletiva do planejamento das disciplinas, a organização das atividades didáticas de forma integrada, os processos avaliativos colegiados, a produção de material didático por áreas de conhecimento e por temas geradores, a revisão crítica de práticas educativas, enfim, um conjunto de ações indispensáveis para a construção de uma perspectiva formativa não fragmentada (PPPLEC, 2014, p. 22).
\end{abstract}

\section{Conforme o Projeto Político-} Pedagógico da LEC (2014, p. 30-31), com o intuito de garantir aos educandos um processo formativo amplo, o curso se articula em três eixos: 
1. O eixo de formação básica que objetiva oferecer uma perspectiva humanista e crítica. Nesse eixo, os componentes curriculares são da área de ciências humanas, sendo cursados pelos alunos das duas habilitações.

2. O eixo de formação específica que objetiva oferecer a formação em uma área de conhecimento específico relacionada à habilitação escolhida, ou seja, Linguagens e Códigos ou Ciências da Natureza.

3. O eixo das práticas integradoras que objetiva integrar os conteúdos trabalhados e contextualizá-los na realidade educacional e comunitária do campo por meio do Relatório do Tempo Comunidade, dos Estágios Supervisionados, das Práticas de Ensino e das AACC.

Nos três primeiros módulos, os alunos cursam componentes curriculares na área de Ciências Humanas e nos seguintes os componentes curriculares da área de formação específica escolhida: Ciências da Natureza ou Linguagens e Códigos. Os alunos egressos que optaram pela primeira são licenciados para atuar como professores de ciências nos anos finais do ensino fundamental e de Química, Física e Biologia no ensino médio e aqueles que optaram pela segunda são licenciados para atuar como professores de Português, Literatura e Inglês.

Para favorecer uma trajetória formativa voltada à criticidade e ao contexto no qual os alunos irão atuar como futuros professores, propõe-se o regime de alternância de períodos educativos na universidade, chamados de Tempos Universidade, e nas regiões onde estão localizadas as comunidades de origem dos estudantes, chamados de Tempos Comunidade. Essas alternâncias de tempos e espaços, semelhantes às alternâncias das Escolas Famílias Agrícolas $(\mathrm{EFA})^{\mathrm{vi}}$, podem ser vistas como uma alternativa metodológica que dialoga com a proposta de educação intercultural, defendida por Santos (2014) e Walsh (2010). Assim, as alternâncias podem ser consideradas como tempos e espaços concretos de "trocas epistemológicas", nos quais os saberes científicos e os das comunidades de origem dos alunos são confrontados de forma dialética com o objetivo de construir novos saberes.

O Tempo Universidade ocorre em dois períodos de cinco semanas nos meses de janeiro/fevereiro e junho/julho na sede da UFVJM em Diamantina. Nesses períodos, além do trabalho com conteúdos específicos em sala de aula, os alunos participam de pesquisas de campo, atividades culturais, seminários, encontros com representantes de movimentos sociais etc. O Tempo Comunidade, por sua vez, é realizado de fevereiro a maio e de agosto a novembro nas regiões de origem dos estudantes, chamadas de polos de alternância. Nesses momentos, 
contextualizam-se os conteúdos trabalhados nos componentes curriculares de Tempo Universidade, executam-se trabalhos de campo de natureza etnográfica, visando desenvolver projetos de intervenção em comunidades campesinas, elabora-se o Relatório do Tempo Comunidade e realizam-se as atividades previstas nas Práticas de Ensino e nos Estágios Supervisionados, integrando assim a pesquisa, o ensino e a extensão.

A alternância dos tempos e espaços, por meio do diálogo com a realidade sociocultural do campo, coloca o conhecimento científico em uma nova perspectiva, enraizada nos saberes e nas práticas locais. Entretanto, vale ressaltar que o Tempo Universidade e o Tempo Comunidade não são dois momentos distintos, mas sim complementares. Eles são planejados para que a construção dos conhecimentos necessários ao educador do campo ocorra tanto no contexto universitário quanto em suas comunidades. Sobre a proposta metodológica das Licenciaturas em Educação do Campo, centrada na alternância de tempos e espaços, Molina e Freitas (2011, p. 28) esclarecem que

Ao organizar metodologicamente o currículo por alternância entre tempo-escola e tempo-comunidade, a proposta curricular da licenciatura objetiva integrar a atuação dos sujeitos educandos na construção do conhecimento necessário à sua formação de educadores, não apenas nos espaços formativos escolares, como também nos tempos de produção de vida nas comunidades onde se encontram as escolas do campo.

Além da alternância de tempos e espaços, outra estratégia do curso para promover uma formação de educadores do campo contextualizada e baseada na proposta de valorização da identidade campesina é o Programa Institucional de Bolsas de Iniciação à Docência para a Diversidade (Pibid Diversidade). Criado em 2010 com o lançamento do edital 002/2010/CAPES/SECAD-MEC - Pibid

Diversidade pela Coordenação de Aperfeiçoamento de Pessoal de Nível Superior (Capes), o programa tem como objetivo atender as licenciaturas interculturais indígenas e do campo, propiciando “... um processo formativo que leve em consideração as diferenças culturais, a interculturalidade do país e suas implicações no trabalho pedagógico" (Portal CAPES, 2013).

Em andamento desde novembro de 2011, o Pibid Diversidade da UFVJM ${ }^{\text {vii }}$ conta com uma equipe formada por professores formadores e alunos da LECUFVJM e professores de escolas do campo na região de abrangência da universidade. Seu objetivo central é "contribuir para a 
formação inicial e continuada de educadores do campo, habilitando-os, a partir da leitura crítica da realidade do campo, a desenvolver uma prática pedagógica contextualizada e transformadora" (Sant'Anna \& Marques, 2015, p. 732). Mediante o desenvolvimento de ações pedagógicas nas escolas e da mobilização das comunidades campesinas em torno de ações interventivas, o programa promove uma formação docente diferenciada e contextualizada, dialogando com a perspectiva de educação intercultural discutida neste trabalho.

Desse modo, a articulação entre universidade e comunidades do campo, propiciada tanto pela alternância de tempos e espaços formativos da LEC-UFVJM como pelo Pibid Diversidade, pode ser vista como uma proposta para o desenvolvimento de competências interculturais entre os professores do campo em formação e em serviço. Segundo Guilherme e Dietz (2015, p. 9),

... as competências interculturais não podem e não devem ser reduzidas a meras 'receitas' de comportamento adequado em certos contextos interculturais (Guilherme, 2013). Em segundo lugar, as competências identificadas como interculturais não podem e não devem ser substancializadas e delimitadas em contraste com as competências intraculturais; ao invés, essas disposições contextualmente articuladas devem ser concebidas como um tipo particular de habitus profissional a ser adquirido, treinado e desenvolvido por professores, assistentes sociais, e outros 'mediadores interculturais'.

No que tange à educação intercultural, Guillherme e Dietz (2015) argumentam que as instituições de educação superior têm responsabilidade social em promover responsabilidade epistêmica e social por meio da sua cooperação em parceria com comunidades periféricas em atividades de pesquisa e em projetos de intervenção locais, nacionais ou internacionais. Citam como exemplo dessas ações projetos internacionais de cooperação intercultural nos quais participaram como o Inter-University Framework Program for Equity and Social Cohesion Policies in Higher Educaction, desenvolvido em 30 universidades, sendo 22 da América Latina, e o projeto InterSaberes, desenvolvido em parceria com a universidade intercultural de Veracruz no México, em regiões indígenas desse país. Nesses projetos, Guilherme e Dietz (2015, p. 13), além de desenvolverem pesquisas etnográficas em pequenas comunidades, promoveram treinamentos e workshops com o objetivo de encontrar "uma maneira adequada de lidar tanto pedagogicamente quando politicamente com diferentes fontes de 
diversidade - não só étnica e cultural, mas também de gênero, orientação sexual e religiosa".

Um dos princípios da educação intercultural sugeridos por Nanni (1988, p. 51-55 apud Fleuri, 2001, p. 54) que pode ser entrevisto no projeto pedagógico da LEC-UFVJM é o da igualdade de oportunidades. Este, vale lembrar, prevê a participação ativa de grupos populares na elaboração e seleção dos conteúdos escolares e estratégias educativas. No curso, o Conselho Consultivo, um dos seus órgãos gestores, é constituído por representantes de movimentos sociais, egressos do PROCAMPO e/ou LEC e discentes e docentes da UFVJM envolvidos com a Educação do Campo. Tem como função principal articular a proposta do curso com os movimentos sociais na discussão do projeto políticopedagógico e de políticas voltadas à Educação do Campo, o que faz com esses sujeitos tenham voz ativa na gestão pedagógica do curso.

Outra característica da LEC-UFVJM que fortalece o princípio da igualdade de oportunidades é a participação frequente de representantes de movimentos sociais do campo em palestras, conferências e encontros promovidos nos Tempos Universidade e Comunidade. Essa participação indica o diálogo entre a proposta do curso de formação de professores e a perspectiva de educação intercultural discutida neste trabalho.

No que tange à adequação de material didático e à adoção de práticas educativas interculturais visando superar o monoculturalismo do conhecimento científico, destacam-se as seguintes ações promovidas pelo curso:

1. A realização de ações interventivas nas escolas e nas comunidades do campo via projetos de pesquisa, ensino e extensão.

2. A elaboração do relatório de Tempo Comunidade, ressignificando a forma de produção de conhecimento no contexto acadêmico.

3. A produção de folders, almanaques, programas de rádio, cartilhas e outros materiais didático-pedagógicos, valorizando aspectos da identidade e da cultura dos sujeitos do campo.

4. A realização de místicas ${ }^{\text {viii }}$ no processo formativo dos estudantes.

5. A realização de saraus durante o Tempo Universidade, com a apresentação de peças, números musicais, poesias, danças etc. sobre a temática da vida no campo.

Entre os desafios enfrentados pelo curso encontra-se o de formar os próprios professores formadores para atuar na educação dos professores do campo, uma vez que a maioria dos professores formadores, além de ter trajetórias de formação distintas das perspectivas teóricas discutidas neste trabalho, não tinha experiência docente em cursos de formação de educadores do campo 
anteriormente. Assim, uma das estratégias adotadas pelo curso para lidar com esse desafio é o trabalho coletivo em sua gestão pedagógica, o qual inclui desde a discussão sistemática e atualização do seu projeto político-pedagógico até o planejamento, a organização e avaliação das atividades didático-pedagógicas do curso.

\section{Considerações finais}

Neste trabalho, foi apresentada e discutida a proposta pedagógica de um curso de formação de professores do campo de uma universidade federal brasileira, o qual tem como objetivo formar professores com habilitação em Ciências da Natureza ou Linguagens e Códigos para atuar nos anos finais do ensino fundamental e no ensino médio de escolas do campo. Para nortear essa reflexão, foram utilizados estudos sobre a ecologia dos saberes de Santos (2014), interculturalidade e Educação do Campo.

Para contextualizar a implantação do curso em questão, a LEC-UFVJM, um panorama histórico do Movimento da Educação do Campo no Brasil foi apresentado, o qual originou políticas e programas do governo federal para o desenvolvimento da educação no contexto rural brasileiro. Entre esses programas, foram destacados neste trabalho $o$
Programa Nacional de Educação na Reforma Agrária (Pronera), o Programa de Apoio à Formação Superior em Licenciatura em Educação do Campo (Procampo) e o Programa Nacional de Educação do Campo (Pronacampo).

Em seguida, o projeto pedagógico do curso foi descrito e analisado. Foram salientados nessa proposta o seu caráter inter/transdisciplinar, o regime de alternância e o Pibid Diversidade, os quais propiciam "trocas epistemológicas", permitindo que os saberes científicos e os das comunidades de origem dos alunos se articulem de forma dialética, ressignificando as formas de produção de conhecimento no contexto acadêmico. Foram também apresentadas atividades pedagógicas do curso que fortalecem os princípios da educação intercultural defendidos por Nanni (1988, p. 51-55 apud Fleuri, 2001), tais como o princípio da igualdade de oportunidades e o da adequação de práticas pedagógicas e de material didático.

Por fim, são apontados desafios que permeiam a formação de professores do campo no Brasil, relacionados à discussão sobre educação intercultural, a saber: como assegurar que propostas de educação intercultural emergentes como as da LECUFVJM sobrevivam em um contexto de crescente exclusão social e instabilidade 
política no mundo contemporâneo? Como trabalhar a questão da interculturalidade em um modelo de universidade que ainda privilegia a formalização, a padronização e a hierarquização do conhecimento? Como ressignificar o papel e as práticas didáticopedagógicas de professores formadores que atuam nessas instituições nas quais prevalece o conhecimento hegemônico da ciência moderna? Essas questões precisam ser discutidas e problematizadas à luz de epistemologias pluralistas, emancipadoras e contra-hegemônicas.

\section{Referências}

Antunes-Rocha, M. I. (2011). Licenciatura em Educação do Campo: histórico e projeto politico pedagógico. In AntunesRocha, M. I., \& Martins, A. A. (Orgs.). Educação do Campo: desafios para a formação de professores (pp. 39-55). Belo Horizonte, MG: Autêntica Editora.

Caldart, R. S. (2009). Educação do Campo: Notas para uma Análise de Percurso. Trab. Educ. Saúde, 7(1), 35-64. DOI: http://dx.doi.org/10.1590/S198177462009000100003.

Carvalho, A. F.; Gois, C. B., \& Soares, M. J. (2011). A mística: um saber pedagógico desenvolvido no campo do estágio em assentamentos. Anais do $V$ Colóquio Internacional Educação $e$ Contemporaneidade. Recuperado de: http://educonse.com.br/2011/cdroom/eixo $\% 202 / \mathrm{PDF} / \mathrm{Microsoft} \% 20$ Word\%20$\% 20 \mathrm{~A} \% 20 \mathrm{M} \% \mathrm{CDSTICA} \% 20 \mathrm{UM} \% 20 \mathrm{SA}$ BER\%20PEDAG\%D3GICO\%20DESENV OLVIDO\%20NO\%20CAMPO\%20DO\%2
0EST\%C1GIO\%20EM\%20ASSENTAME NTOS.pdf

Cordeiro, G. N. K., Reis, N. S., \& Hage, S. M. (2011). Pedagogia da Alternância e seus desafios para assegurar a formação humana dos sujeitos e a sustentabilidade do campo. Em Aberto, 24(85), 115-125.

Decreto $n .7 .352$, de 4 de novembro de 2010. (2010, 4 de novembro). Dispõe sobre a Política de Educação do Campo e o Programa Nacional de Educação na Reforma Agrária - PRONERA. Recuperado de: http://portal.mec.gov.br/docman/marco2012-pdf/10199-8-decreto-7352-de4-denovembro-de-2010/file

Edital de Convocação n. 9, de 29 de abril de 2009 (2009, 29 de abril). Convoca as Instituições Públicas de Educação Superior - IES públicas - para apresentarem projetos de Cursos de Licenciatura em Educação do Campo para a formação de professores da educação básica nas escolas situadas nas áreas rurais. Recuperado de: http://portal.mec.gov.br/dmdocuments/edit al_procampo_20092.pdf

Edital de Seleção SESU/SETEC/SECADI $n$. 2, de 31 de agosto de 2012 (2012, 31 de agosto). Chamada Pública para seleção de Instituições Federais de Educação Superior - IFES e de Institutos Federais de Educação, Ciência e Tecnologia - IFET, para criação de cursos de Licenciatura em Educação do Campo, na modalidade presencial. Recuperado de: http://pronacampo.mec.gov.br/images/pdf/ edital_\%2002_31082012.pdf

Estermann, J. (2010). Interculturalidad: Vivir la Diversidad. La Paz: Instituto Superior Ecumênico Andino de Teologia.

Fleuri, R. M. (2001). Desafios à educação intercultural no Brasil. Educação, 
Sociedade \& Cultura, 45-62. Recuperado de:

http://www.fpce.up.pt/ciie/revistaesc/ESC1 6/16-2.pdf

Freitas, H. C. de A. (2011). Rumos da Educação do Campo. Em Aberto, 24(85), p. 35-49.

Guilherme, M., \& Dietz, G. (2015). Difference in Diversity: Multiple perspectives on multi-, inter-, and transcultural conceptual complexities. Journal of Multicultural Discourses, 10(1), 1-21. DOI:http://dx.doi.org/10.1080/17447143.2 $\underline{015.1015539}$

Manual de Operações do Programa Nacional de Educação na Reforma Agrária. (2016). Recuperado de:

http://www.incra.gov.br/sites/default/files/ uploads/reforma-agraria/projetos-eprogramas/pronera/manual_pronera_18.01.16.pdf

Molina, M. C., Montenegro, J. L. A., \& Oliveira, L. L. N. A. (2009). Das Desigualdades aos Direitos: a Exigência de Políticas Afirmativas para a Promoção da Equidade Educacional no Campo. Raízes, 29(1), 174-190.

Molina, M. C., \& Freitas, H. C. de A. (2011). Avanços e Desafios na Construção da Educação do Campo. Em Aberto, 24(85), p. 17-31.

Molina, M. C., \& Antunes-Rocha, M. I. (2014). Educação do Campo, História, Práticas e Desafios no Âmbito das Políticas de Formação de Educadores: Reflexões sobre o Pronera e o Procampo. Revista Reflexão e Ação, 22(2), 220-253. DOI: http://dx.doi.org/10.17058/rea.v22i2. $\underline{5252}$.

Plano de Desenvolvimento Institucional da Universidade Federal dos Vales do
Jequitinhonha e Mucuri - PDI 2012-2016. (2012). Recuperado de: http://www.ufvjm.edu.br/universidade/insti tucional.html?lang $=\mathrm{pt} \_$BR.utf $8 \% 2 \mathrm{C}+\mathrm{pt} \_\mathrm{B}$ R.UT

Portal CAPES. Pibid Diversidade. (2013, 6 de setembro). Recuperado de: http://www.capes.gov.br/educacaobasica/capespibid/pibid-diversidade

Portal Polo Jequitinhonha. UFMG. (2017, 4 de abril). Recuperado de: https://www2.ufmg.br/polojequitinhonha/ O-Vale/Sobre-o-Vale

Portaria $n^{\circ} 86$, de 1 de fevereiro de 2013. (2013, 1 de fevereiro). Institui o Programa Nacional de Educação do Campo PRONACAMPO e define suas diretrizes gerais. Recuperado de: http://pronacampo.mec.gov.br/images/pdf/ port_86_01022013.pdf

Projeto Político Pedagógico da Licenciatura em Educação do Campo da Universidade Federal dos Vales do Jequitinhonha e Mucuri. (2014). Recuperado de: http://site.ufvjm.edu.br/lec/projetopedagogico/

Sant'Anna, P.A.; \& Marques, L.O.C. (2015). Pibid Diversidade e a Formação de Educadores do Campo. Educação \& Realidade, 40(3), 651-961. DOI: http://dx.doi.org/10.1590/2175-623645795

Santos, B. S. (2014). Ecologies of Knowledges. In __ Epistemologies of the South: Justice against Epistemicide (pp.188-211). Boulder, Colo: Paradigm Publishers.

Secretaria de Educação Continuada, Alfabetização, Diversidade e Inclusão: Apresentação. (s/d). Recuperado de: http://portal.mec.gov.br/secretaria-de- 
educacao-continuada-alfabetizacao-

diversidade-e-inclusao/apresentacao

UNESCO (2006). UNESCO Guidelines on Intercultural Education. Paris: UNESCO. Recuperado de: http://unesdoc.unesco.org/images/0014/00 $\underline{1478 / 147878 \text { e.pdf }}$

Walsh, C. (2009). Interculturalidad, Estado, Sociedad: Luchas (de)coloniales de Nuestra Época. Quito: Universidad Andina Simón Bolivar, Ediciones AbyaYala.

(2010). Interculturalidad crítica y educación intercultural. In Viaña, J., Tapia, L., \& Walsh, C. (Eds.), Construyendo Interculturalidad Crítica (pp. 75-96). La Paz: Instituto Internacional de Integración.

\footnotetext{
i Todas as citações de obras estrangeiras foram traduzidas para o português pelo autor deste trabalho.

\begin{abstract}
ii Walsh (2009, p. 15) utiliza o termo "de-colonial", suprimindo o "s" de "descolonial" para marcar uma distinção com o significado dessa palavra em espanhol. Segundo a autora, pretende-se com o "de-colonial" provocar um posicionamento contínuo de transgressão, intervenção e insurgência.

iii Conforme Cordeiro et al. (2011, p. 116), a Pedagogia da Alternância é "uma proposta pedagógica e metodológica capaz de atender as necessidades da articulação entre escolarização e trabalho, propiciando a esses indivíduos o acesso à escola sem que tenham que deixar de trabalhar".
\end{abstract}

iv No projeto político pedagógico do curso em questão, utiliza-se com mais frequência o termo "componente curricular" ao invés de "disciplina".

v Na nova versão do Projeto Político Pedagógico de 2017, ainda a ser aprovada pelos órgãos superiores da UFVJM, o Relatório de Tempo Comunidade passou a ser chamado de Trabalho Interdisciplinar do Tempo Comunidade.

vi As EFAs (Escolas Famílias Agrícolas) são escolas de ensino profissionalizante, financiadas por entidades públicas e privadas, voltadas para jovens do meio rural. Nessas escolas, os alunos estudam em regime de alternância.

vii Inicialmente, o Pibid Diversidade da UFVJM foi gerido por professores formadores que atuavam no Procampo, iniciado em 2010. Quando o Pibid Diversidade foi instituído na universidade em 2011, a LEC ainda não havia sido implantada.

viii Conforme Carvalho, Gois e Soares (2011), as místicas fazem parte da história do Movimento dos Trabalhadores Sem Terra (MST). São encenações, em formato de peças teatrais, que mostram momentos marcantes da luta dos sujeitos do campo em prol dos seus direitos. Na LEC-UFVJM, as místicas são geralmente apresentadas no início de práticas educativas como "um aquecimento" ou no final como uma reflexão sobre o processo de aprendizagem.

Recebido em: 25/02/2017

Aprovado em: 27/06/2017

Publicado em: 31/07/ 2017
Como citar este artigo / How to cite this article / Como citar este artículo:

APA:

Marques, L. O. C. (2017). Interculturalidade na formação de professores do campo: análise de uma experiência. Rev. Bras. Educ. Camp., 2(2), 447-471. DOI: $\quad$ http://dx.doi.org/10.20873/uft.25254863.2017v2n2p447

\section{ABNT:}

MARQUES, L. O. C. Interculturalidade na formação de professores do campo: análise de uma experiência. Rev. Bras. Educ. Camp., Tocantinópolis, v. 2, n. 2, p. 447-471, $2017 . \quad$ DOI: http://dx.doi.org/10.20873/uft.2525$\underline{4863.2017 \mathrm{v} 2 \mathrm{n} 2 \mathrm{p} 447}$

\section{ORCID}

Luiz Otávio Costa Marques

http://orcid.org/0000-0001-7139-3137 